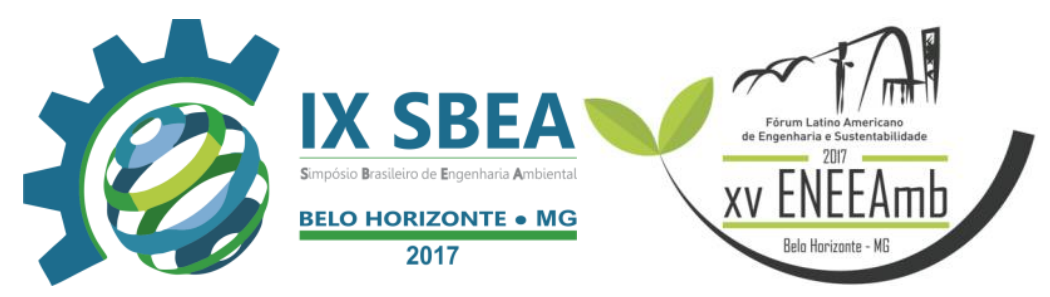

\title{
AVALIAÇÃO ESPAÇO-TEMPORAL DA QUALIDADE DA ÁGUA NA LAGOA DO PARQUE POLIESPORTIVO DE ITAPETINGA, BAHIA
}

Romário Oliveira de Santana - engenheiro.romario@ hotmail.com

Universidade Estadual do Sudoeste da Bahia

Flávia Mariani Barros- mariamariani@yahoo.com.br

Universidade Estadual do Sudoeste da Bahia

Danilo Paulúcio da Silva - dpaulucio@ uesb.edu.br

Universidade Estadual do Sudoeste da Bahia

Alison Silva dos Santos - alisonss@outlook.com

Universidade Estadual do Sudoeste da Bahia

Maxwell Christian Silva Canaverde Oliveira - maxwell_dm@hotmail.com

Universidade Estadual do Sudoeste da Bahia

Lídia Raíza Sousa Lima Chaves Trindade - lidiaraiza@ hotmail.com

Universidade Estadual do Sudoeste da Bahia

Mayana Silva Bessa Leite- mayanabessa@ hotmail.com

Universidade Estadual do Sudoeste da Bahia 




\section{RESUMO}

Objetivou-se com o presente trabalho quantificar as variáveis limnológicas na Lagoa do Parque Poliesportivo de Itapetinga. Os dados utilizados no presente estudo foram coletados nos meses de agosto, setembro e outubro em diferentes pontos seguindo as recomendações na legislação para coleta e amostragem em ambientes lênticos. Para melhor analise do resultados os dados foram especializados por meio de técnicas de interpolação de dados em ambiente de Sistema de Informação Geográfica. Nas amostras foram realizadas análises de condutividade elétrica, oxigênio dissolvido, potencial hidrogeniônico $(\mathrm{pH})$ e turbidez. Dentre as variáveis observadas o $\mathrm{pH}$ e turbidez apresentaram valores dentro do limite estabelecido pela Resolução CONAMA 357/2005 para rios de Classe 2. Nos meses de agosto e setembro os valores de oxigênio dissolvido estavam em conformidade com a legislação, já no mês de outubro os valores foram abaixo do permitido, o que pode ter sido ocasionado por lançamento de efluentes no período de estudo. Comparando os resultados de condutividade elétrica com os encontrados na literatura percebe-se que no período de estudo ocorreu uma contribuição de nutrientes que podem ser provenientes de efluentes.

Palavras-chave: lênticos, recursos hídricos, sensoriamento remoto.

\section{INTRODUÇÃO/OBJETIVO}

A caracterização de aspectos relevantes que permitam diagnosticar as mudanças que ocorrem no uso e ocupação do solo é de fundamental importância nos softwares voltados para o monitoramento ambiental. Estes visam avaliar os impactos das atividades antrópicas nas bacias hidrográficas e seus efeitos nos ecossistemas, sendo amplamente utilizados na gestão da qualidade da água. (QUEIROZ et al., 2010).

O monitoramento ambiental utiliza variáveis que possam representar a situação dos corpos d'água. Segundo BRAGA et al., (2005), a utilização de indicadores da qualidade da água constitui-se na avaliação da aplicação de variáveis e sua correlação com as mudanças na bacia hidrográfica, seja elas de origem natural ou a partir das interferências humanas.

Com o avanço das técnicas de geoprocessamento, tornou-se possível coletar mais informações, com uma maior precisão e de forma mais rápida, permitindo extrair variáveis específicas de acordo com o objetivo do pesquisador. Essas tarefas, de acordo com RODRIGUES (2001), são passíveis a utilização de SIG (Sistema de informações geográficas), que abrangem ferramentas digitais que possibilitam a aquisição, análise e informações espaciais.

Segundo BURROUGH (1986), em estudos relacionados ao meio ambiente, preservação e manutenção dos recursos naturais, como destaque o monitoramento da qualidade da água, a utilização do SIG na pesquisa auxiliará na previsão de determinados fenômenos e no planejamento adequado para a área de estudo, considerando que as variáveis obtidas e armazenadas representará um modelo que simule um evento real. 


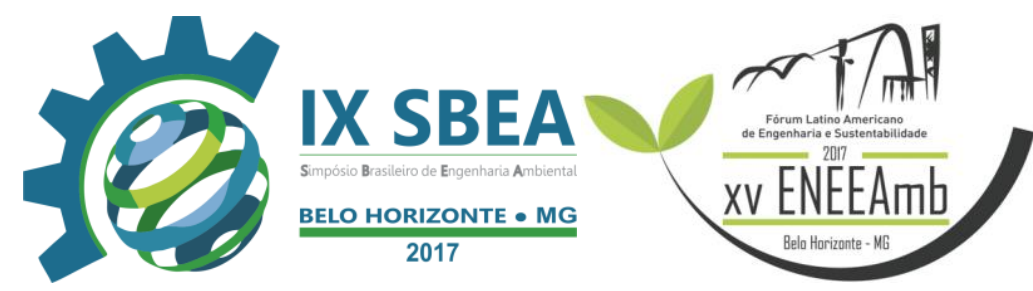

Diante do exposto, o presente estudo teve como objetivo realizar uma avaliação espaço-temporal da qualidade da água na Lagoa do Parque Poliesportivo de Itapetinga, Bahia.

\section{METODOLOGIA}

O presente estudo foi realizado no reservatório da Lagoa do Parque Poliesportivo, situada no município de Itapetinga, sudoeste da Bahia. Considerando o sistema de projeção Universal Transversa de Mercator (UTM), está contida na zona 24, entre os paralelos 8313263 e $8313005 \mathrm{~m}$ e meridianos 364851 e $365060 \mathrm{~m}$. A Lagoa apresenta uma área de drenagem de $27398,08 \mathrm{~m}^{2}$ e um perímetro igual a $878,87 \mathrm{~m}$.

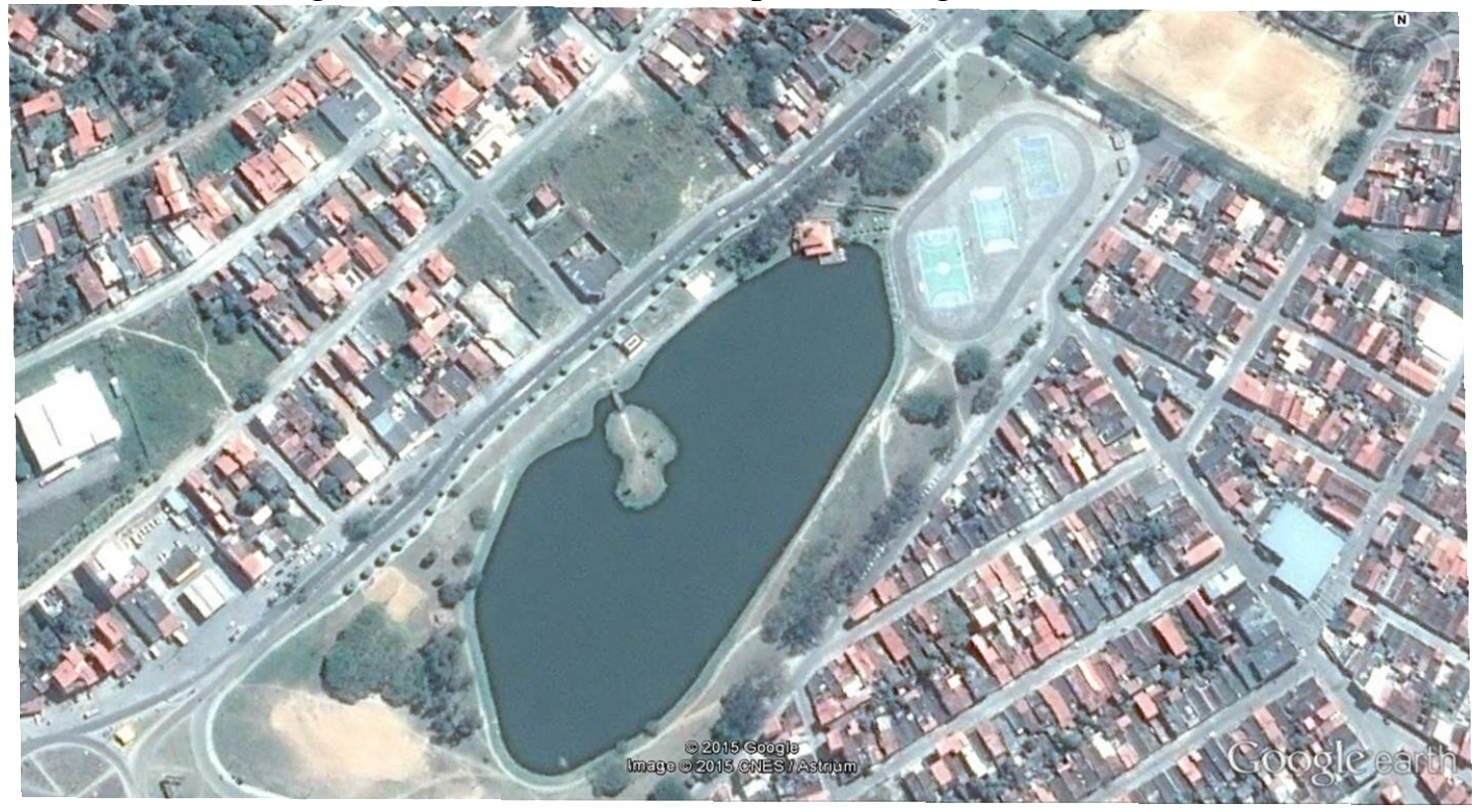

Figura 1. Localização da Lagoa do Parque Poliesportivo de Itapetinga, Bahia.

Fonte: Google Maps.

A avaliação da variabilidade espaço-temporal da qualidade da água na Lagoa, foi realizada a partir de campanhas de coletas de amostras de água nos meses de agosto, setembro e outubro de 2013. Foram selecionados seis pontos de coleta, sendo que a distribuição espacial foi realizada segundo o preconizado pela NBR 9898/87 para amostragem em ambientes lênticos. Os pontos de coleta foram demarcados e georreferenciados a partir de um GPS de navegação.

A coleta e armazenamento das amostras água da Lagoa foi realizada segundo o recomendado pelo Guia Nacional de Coleta e Preservação de amostras da ANA/CETESB (2012). Após coleta e armazenamento as amostras foram transportadas para o Laboratório de Solos da Universidade Estadual do Sudoeste da Bahia - Campus Itapetinga. 


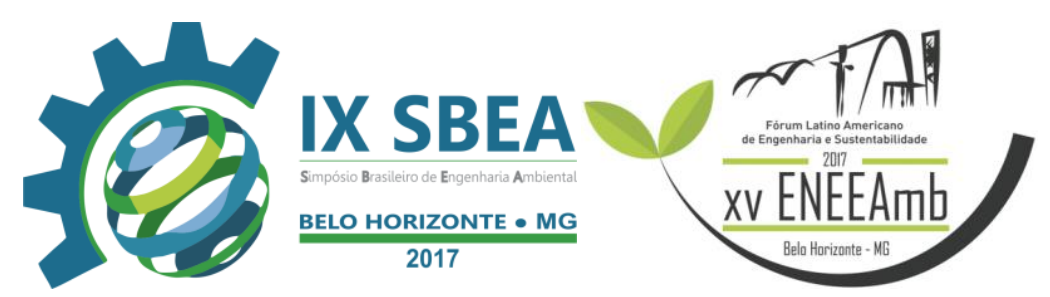

As variáveis limnológicas quantificadas foram: $\mathrm{pH}$, condutividade elétrica, turbidez e oxigênio dissolvido. A quantificação das variáveis nas amostras de água coletada ocorreram segundo as metodologias descritas em MATOS (2014).

Para determinação do potencial hidrogeniônico, foi utilizado o método eletrométrico, com peagâmetro marca Digimed, modelo DM - 22. A condutividade da água foi obtida por meio de condutivímetro marca Digimed, modelo DM - 32. A variável turbidez foi determinada pelo método nefelométrico, utilizando-se um turbidímetro, Marca Digimed, modelo DM-TU - 0 a 1000 UNT. As concentrações de oxigênio dissolvido foram obtidas pelo método químico de Winkler, modificado pela ázida de sódio, que compreende diversas fases.

Para análise espacial da qualidade da água os dados foram georreferenciados, convertidos no formato vetorial de pontos e interpolados com o método de interpolação Inverse Distance Weighted (IDW), no software ArcGIS 10.2. O IDW é um método de interpolação espacial determinista, sendo um dos métodos mais utilizados nos estudos que envolvem interpolação de dados (LU \& WONG, 2008). O método realiza a espacialização das variáveis através da ponderação de pesos para cada um dos $n$ pontos que apresentam uma maior proximidade, logo quanto mais próximo do ponto a ser estimado, maior será seu peso em relação aos outros pontos (GARDIMAN JUNIOR et al. 2012).

Obtiveram-se as variáveis estatísticas com emprego do software SAEG, versão 9.1.De acordo com o artigo 42 da Resolução CONAMA 357/2005 (BRASIL, 2005) enquanto não aprovado o enquadramento o corpo d'água de águas doces são consideradas classe 2. Desta forma, os resultados encontrados nas coleta foram comparados com os padrões da qualidade para classe 2 da Resolução CONAMA 357.

\section{RESULTADOS E DISCUSSÃO}

Na Figura 2 estão apresentados os mapas com a espacialização dos valores de turbidez na Lagoa do Parque Poliesportivo de Itapetinga, Bahia. Avaliando a turbidez média entre os meses analisados a variação apresentada foi pequena ficando entre 15,41 e 23,33 NTU. Os valores encontrados estão abaixo de 100 NTU, logo estão em conformidade com o permitido pela Resolução CONAMA357/05 (BRASIL, 2005) para corpos d'água doce classe 2.

DONADIO et al.(2005), verificando a influência dos diferentes usos do solo nas variáveis de qualidade da água em nascentes da bacia do Córrego Rico, encontraram valores de turbidez entre 2,4 e 7,9 NTU para nascentes com vegetação natural remanescente e valores entre 12,2 e 26,1 NTU para nascentes com a presença de uso agrícola. Esses valores corroboram com os encontrados no presente estudo e indica que a Lagoa apresenta bons níveis de manutenção da vegetação natural. 



Figura 2 - Espacialização da turbidez na Lagoa do Parque Poliesportivo de Itapetinga, Bahia.

MARMONTEL E RODRIGUES (2015), realizando uma avaliação qualitativa em nascentes com diferentes coberturas do solo e conservação da vegetação em seu entorno, encontraram valores de turbidez entre 12,6 e 173,6 UNT. Segundo os autores cursos d'água com valores de turbidez superior ao estabelecido na legislação evidenciam a degradação devido ao despejo de efluentes, acesso de animais ao olho d'água e ausência de mata ciliar.

A CONAMA 357/05 não estabelece valores mínimos e/ou máximos para condutividade elétrica (CE) então nesse caso utiliza-se o valor determinado pela CETESB (2012), que é $100 \mu \mathrm{S} / \mathrm{cm}$, sendo considerados, possivelmente, como ambientes impactados, os corpos d'água com condutividade elétrica acima desse valor.

Os valores para CE nas campanhas de coleta (Figura 3) ficaram entre 1103,40 e $1202,00 \mu \mathrm{S} / \mathrm{cm}$, estando acima dos padrões estabelecidos, o que indica que a área de estudo tem recebido cargas de efluentes e aporte de nutrientes do solo, o que pode está ocasionando uma elevação da condutividade elétrica. Segundo SANTOS et al.(2011), a variação sazonal da precipitação é outro fator que pode ocasionar o aumento nos valores de condutividade, pois com a chuva ocorre a lixiviação de alguns nutrientes para os cursos d'água. 


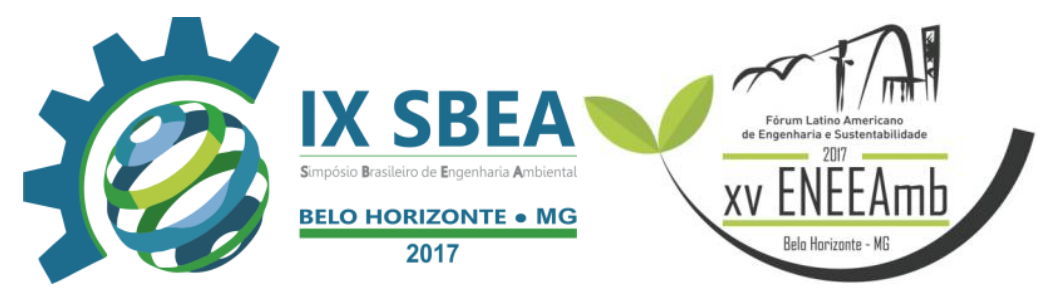

\section{Espacialização da Condutividade Elétrica}
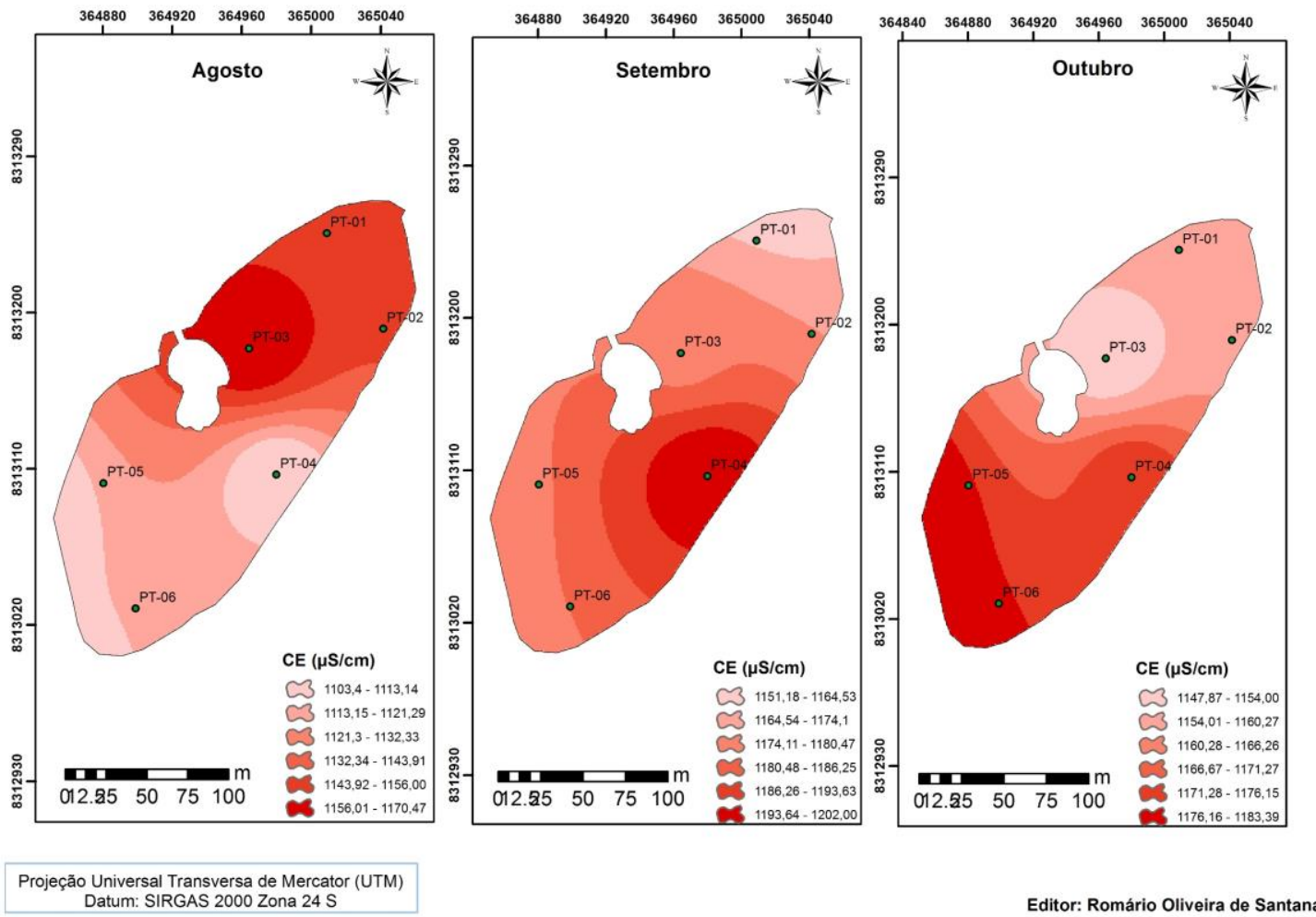

Projeção Universal Transversa de Mercator (UTM) Datum: SIRGAS 2000 Zona 24 S

Editor: Romario Oliveira de Santana

Figura 3 - Espacialização da condutividade elétrica na Lagoa do Parque Poliesportivo de Itapetinga, Bahia.

BLEICH et al. (2009) avaliando a variação temporal e espacial das características limnológicas de um ecossistema lótico no Cerrado do Mato Grosso, encontraram valores médios de CE, variando de $20 \mu \mathrm{S} \mathrm{cm}^{-1}$ a $120 \mu \mathrm{S} \mathrm{cm}^{-1} \mu \mathrm{S} \mathrm{cm} \mathrm{cm}^{-1}$. Segundo os autores, os valores encontrados podem estar associados ao lançamento de elfuentes domésticos e industrias no corpo hídrico.

Na Figura 4 estão apresentados os valores de $\mathrm{pH}$ especializados para os meses de análise. Os valores para o potencial hidrogeniônico apresentaram uma pequena variação entre 7,84 e 8,02, indicando valores aceitáveis de acordo com o recomendado na CONAMA 357/2005. Os valores de pH também estão em conformidade com os estabelecidos na Portaria 2914/2011 do Ministério da Saúde (Brasil, 2011), que estabelece que os valores de pH devem ficar entre 6,0 e 9,5.

De acordo com VON SPERLING (2014), a elevação do potencial hidrogeniônico em ambientes aquáticos pode relacionada com as características geológicas da área, despejos domésticos e industriais de efluentes e/ou à presença de plantas aquáticas. $\mathrm{O}$ aumento do $\mathrm{pH}$ também pode ocorrer devido à mineralização do material orgânico do meio. 


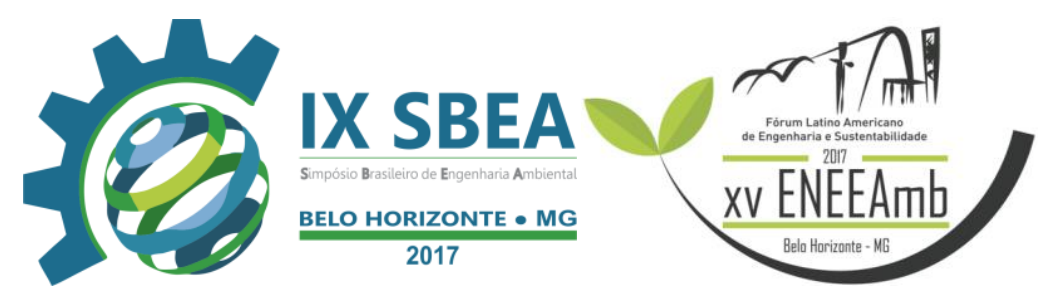

\section{Espacialização do potencial hidrogeniônico $(\mathrm{pH})$}
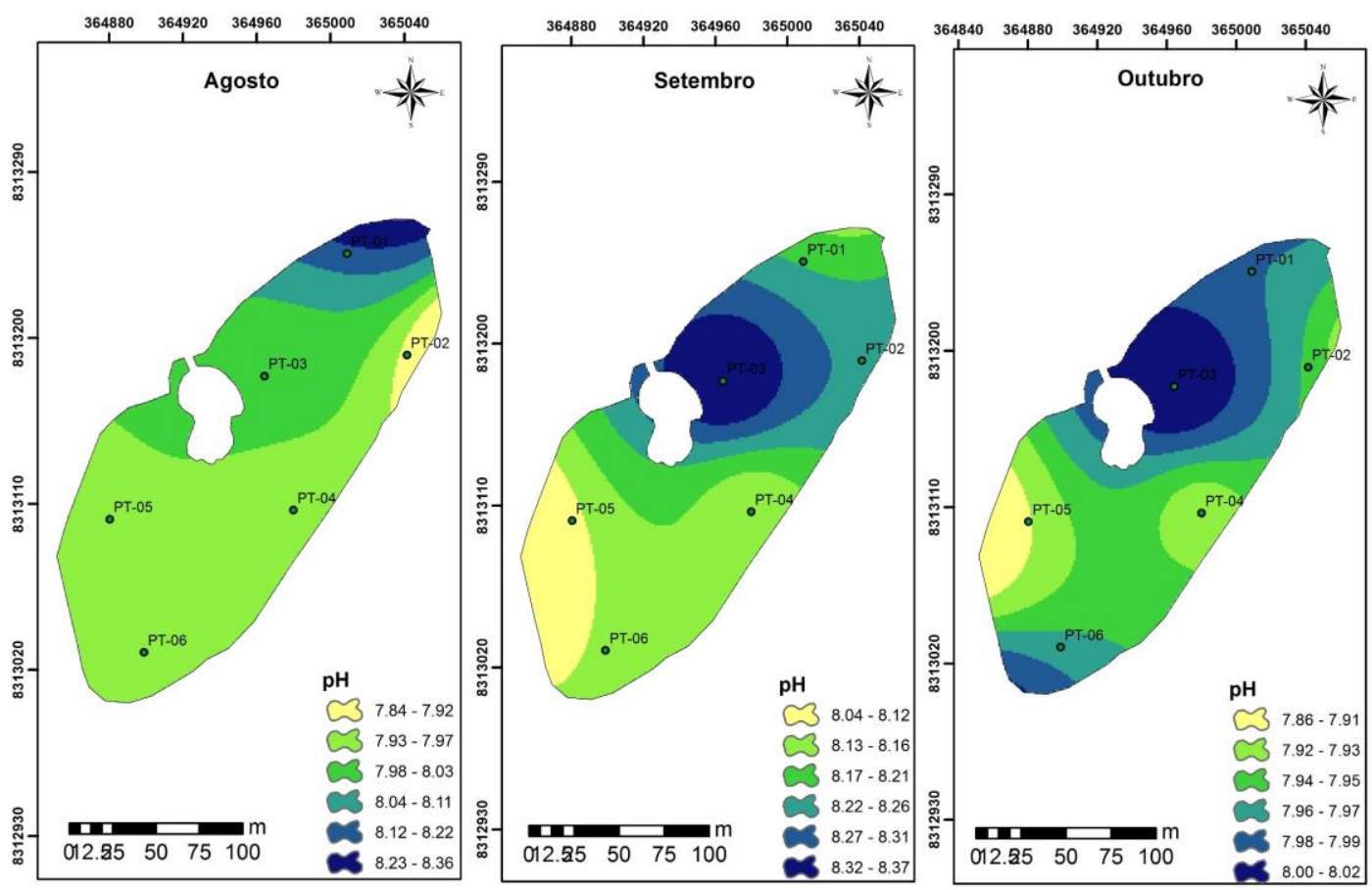

Projeção Universal Transversa de Mercator (UTM) Datum: SIRGAS 2000 Zona 24 S

Figura 4 - Espacialização do pH na Lagoa do Parque Poliesportivo de Itapetinga, Bahia.

A concentração de OD é a mais importante, pois ela é capaz de expressar a qualidade do ambiente aquático (VON SPERLING, 2014). O OD estão apresentados (Figura 4) neste estudo variaram de 4,14 a 7,50 mg/L. Os meses de agosto e setembro apresentaram valores entre 6,51 a 7,50 mg/L e 5,78 a 6,26 mg/L, respectivamente, estando dentro dos padrões estabelecido pela Resolução CONAMA 357/05, a qual determina que os valores de OD para águas doce classe 2 não devem ser inferiores a $5 \mathrm{mg} / \mathrm{L} \mathrm{de} \mathrm{O}_{2}$.

O mês de outubro apresentou valores de oxigênio dissolvido entre 4,14 e 4,70 $\mathrm{mg} / \mathrm{L}$, esses valores estão abaixo do limite recomendado pela legislação. Esses baixos valores podem ter sido ocasionados por uma maior contribuição de despejos domésticos na Lagoa no período de estudo. Segundo Santos et al. (2013), o lançamento de esgoto doméstico e resíduos sólidos pode afetar diretamente a disponibilidade de oxigênio dissolvido na água.

Outro fator importante que pode ter interferido nos valores de oxigênio, foi a temperatura. A temperatura é uma variável que afeta diretamente a solubilidade do oxigênio na água. Os meses de agosto, setembro e outubro apresentaram temperatura média de $21,31{ }^{\circ} \mathrm{C}, 21,20{ }^{\circ} \mathrm{C}$ e $24,65^{\circ} \mathrm{C}$, respectivamente. 


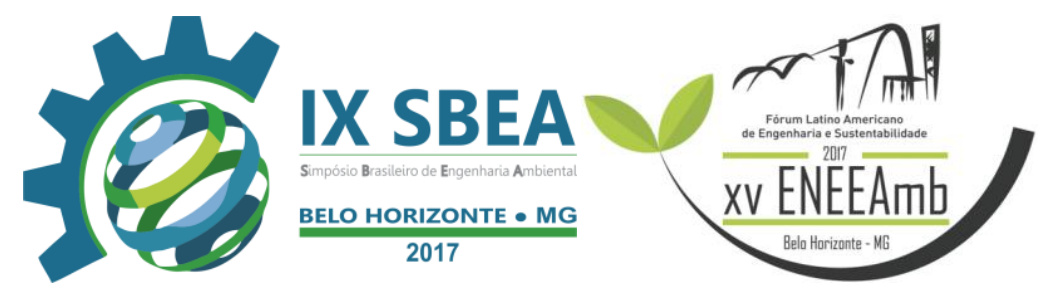

Espacialização do Oxigênio Dissolvido (OD)

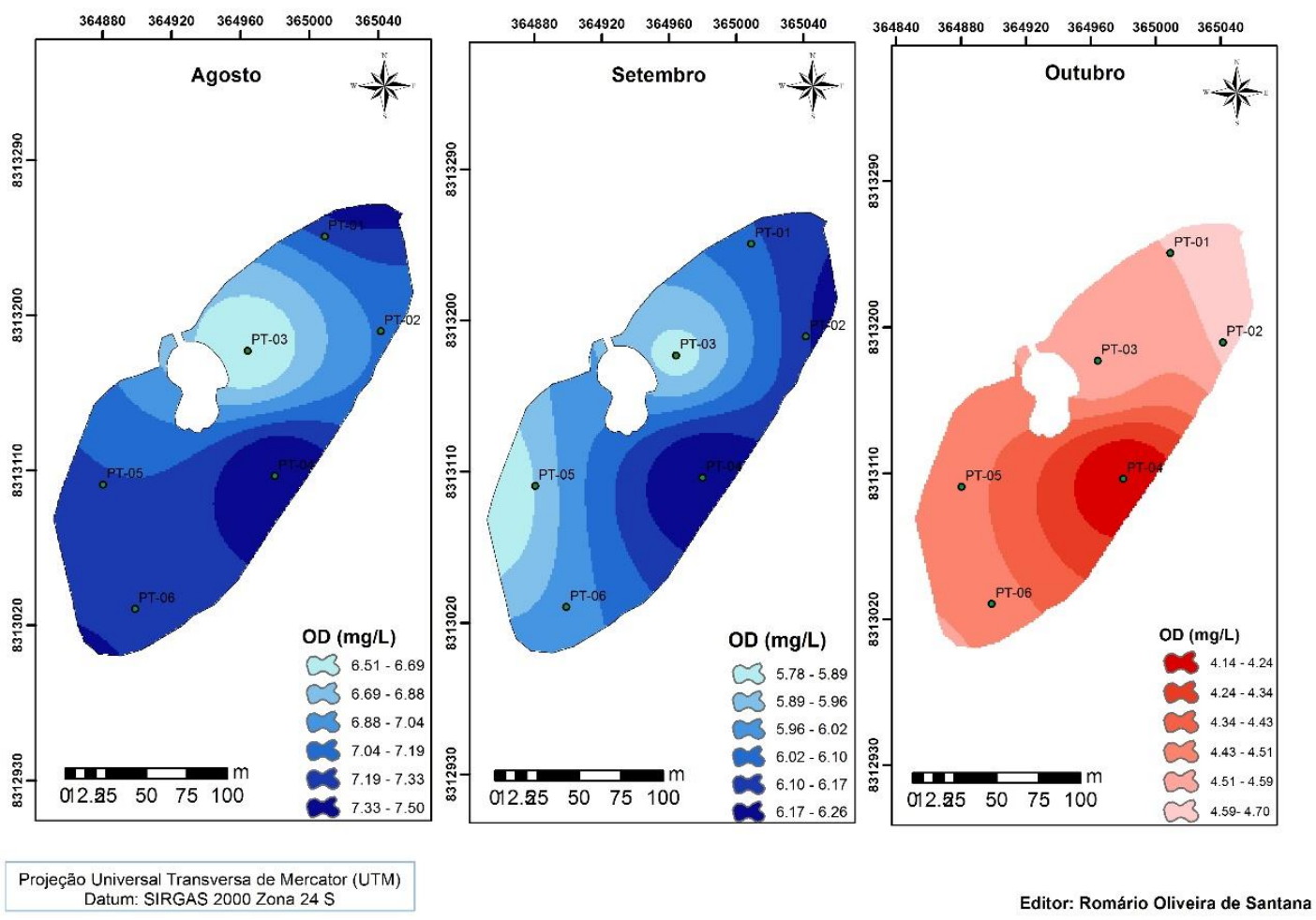

Figura 4 - Espacialização do oxigênio dissolvido na Lagoa do Parque Poliesportivo de Itapetinga, Bahia.

TRINDADE et al. (2016) analisando a espacialização do oxigênio dissolvido na Lagoa do Parque Poliesportivo de Itapetinga, encontrou valores de oxigênio dissolvido entre 4,47 a 6,15 mg/L. Segundo os autores os valores abaixo de $5 \mathrm{mg} / \mathrm{L}$ indicam grande impacto neste ambiente, além do lançamento de esgoto doméstico e resíduos sólidos por estabelecimentos próximos ao local.

MOURA et al. (2013) avaliando parâmetros de indicadores da qualidade de água para verificar o estado de conservação das represas do rio Ipatinga encontrou valores médios de oxigênio dissolvido de 6,91, 5,30 e 5,68 mg/L para as represas I,II e III, respectivamente. Sendo os valores encontrados dentro dos padrões estabelecidos pela CONAMA 357/2005 e próximos aos encontrados no presente estudo.

\section{CONCLUSÕES/RECOMENDAÇÕES}

A turbidez apresentou uma variação entre 15,41 e 23,33 NTU, estando dentro do estabelecido pela legislação para corpos d'água doce condicão classe II. A condutividade elétrica apresentou valores entre 1103,40 e $1202,00 \mu \mathrm{S} / \mathrm{cm}$ o que indica inconformidade com o recomendado pela CETESB (2013). Os valores de oxigênio dissolvido observados 


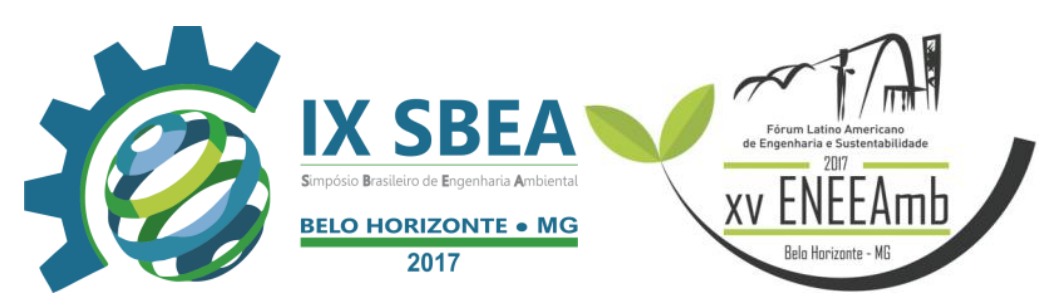

neste estudo apresentaram uma variação de 4,14 a 7,50 mg/L. A terceira campanha de coleta foi a única que apresentou valores abaixo do estabelecido pela CONAMA 357/05 para rios classe 2 . Os valores observados para $\mathrm{pH}$ apresentou um amplitude média pequena variando entre 7,84 e 8,04 .

\section{REFERÊNCIAS BIBLIOGRÁFICAS}

BRAGA, B.; HESPANHOL, I.; CONEJO, J. G. L.; BARROS, M. T. L.; SPENCER, M.; PORTO, M.; NUCCI, N.; JULIANO, N.; EIGER, S. (2003). Introdução à Engenharia Ambiental. Prentice Hall, São Paulo - SP. 305 p.

BRASIL 2005.Resolução CONAMA (Conselho Nacional de Meio Ambiente). Resolução n. ${ }^{\circ}$ 357, de 17 de março de 2005. Diário Oficial da República Federativa do Brasil, Brasília, 2005.

BURROUGH, P. A. (1986). Principles of geographical information systems for land resources assessment. Oxford: Clarendon Press.193 p.

DONADIO, N. M. M.; GALBIATTI, JOÃO ANTONIO; PAULA, RINALDO CÉSAR DE. Qualidade da água de nascentes com diferentes usos do solo na Bacia Hidrográfica do Córrego Rico, São Paulo, Brasil. Revista de Engenharia Agrícola, Jaboticabal, v. 25, n.1, p. 115-125, 2005.

GARDIMAN JUNIOR, B. S.; MAGALHÃES, I. A. L.; FREITAS, C. A. A.; CECÍlLIO, R. A. Análise de técnicas de interpolação para espacialização da precipitação pluvial na bacia do rio Itapemirim (ES). Ambiência (UNICENTRO), v. 8, p. 61-71, 2012.

LEITE, M. S. B.; BARROS, F. M.; DA SILVA, D. P.; DE SANTANA, R. O.; AMORIM, J. S.; DE CARVALHO, S. R. Comparação entre metodologias de amostragem de água para quantificação de variáveis limnológicas em ambiente lótico. Revista Ambiente \& Água, v. 12, p. 136-145, 2016.

LIMA, E.M., PINTO; J.E.S. Bacia do rio Catolé, Bahia - Brasil: bases geoambientais e socioeconômicas para a gestão da água e do solo. Revista Geográfica de América Central Número Especial. EGAL, 2011- Costa Rica II Semestre 2011 pp. 1-11.

MARMONTEL, C. V. F.; A. Avaliação qualitativa de nascentes com diferentes coberturas do solo e conservação da vegetação em seu entorno no córrego Pimenta. Scientia Agraria Paranaensis, v. 14, p. 53-59, 2015.

MATOS, ANTÔNIO TEIXEIRA DE. Qualidade do Meio Físico Ambiental: Práticas de Laboratório. 1. Ed. Viçosa, MG. Editora UFV. 2012. 150p. 


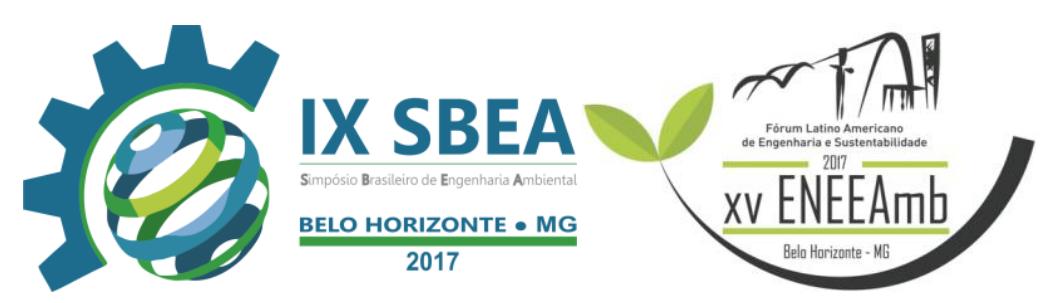

MOURA, V.M.; BRITO, S.M.O. E SILVA, A.B. Avaliação dos Parâmetros Indicadores da Qualidade da Água para Verificar o Estado de Conservação das Represas do Rio Ipitanga, Salvador, BA, Brasil. Revista Virtual de Química, Vol. 5, No.5, p.869-890, 2013.

PINHEIRO, A.; FAHT, G. ; SILVA, M. R. . Determinação do coeficiente de reaeração em rios através do uso do traçador gasoso GLP. Engenharia Sanitária e Ambiental, v. 17, p. 107-116, 2012.

RAMOS, C.C. Mapeamento da fragilidade ambiental da bacia hidrográfica do rio catolé com uso de ferramenta SIG. 2008. 40fl. Monografia do curso de especialização em Meio Ambiente e Desenvolvimento, UESB - Itapetinga: UESB. 2008.

RODRIGUES, J. B. T.; ZIMBACK, C. R. L. e PIROLI, E. L.. Utilização de sistema de informação geográfica na avaliação do uso da terra em Botucatu (SP). Revista Brasileira Ciência do Solo. 2001, v.25, n.3, pp.675-681.

SANTOS, A. R. dos. Caracterização morfológica, hidrológica e ambiental da bacia hidrográfica do rio Turvo Sujo, micro região de Viçosa, MG. Tese (Tese de Doutorado em Engenharia Agrícola), Universidade Federal de Viçosa, UFV, Viçosa, 2001. $125 \mathrm{p}$.

SANTOS, Q. R.; FRAGA, M. S.; ULIANA, E. M.; REIS, A. S. ; BARROS, F. M. . Monitoramento da qualidade da água em uma seção transversal do rio Catolé, ItapetingaBA. Enciclopédia Biosfera, v. 9, p. 1503-1519, 2013.

TRINDADE, L. R. S. L. C. ; SANTANA, R. O. ; SANTOS, A. S. ; BARROS, F. M. . Variação Espacial da Qualidade da Água na Lagoa do Parque Poliesportivo de Itapetinga, Bahia.. In: Giovanni Seabra. (Org.). Educação Ambiental e Biogeografia. 1ed.João Pessoa: Editoria Universitária - UFPB, 2016, v. 5, p. 452-462.

VON SPERLING, M. V. Introdução a qualidade das águas e ao tratamento de esgotos. Departamento de engenharia sanitária e ambiental, universidade federal de Minas Gerais - BH.4 ed. p. 107, 2014. 